www.jmscr.igmpublication.org

Impact Factor 5.84

Index Copernicus Value: 71.58

ISSN (e)-2347-176x ISSN (p) 2455-0450

crossref DOI: _https://dx.doi.org/10.18535/jmscr/v5i9.85

Journal Of Medical Science And Clinical Research

IGM Publication

An official Publication of IGM Publication

\title{
Inconsiderate try in of Complete Denture Prosthesis - An Iatrogenic Failure
}

\author{
Authors \\ Khurshid A Mattoo ${ }^{1 *}$, Sarwar $\mathrm{S}^{2}$ \\ ${ }^{1 * A s s i s t a n t ~ P r o f e s s o r, ~ D e p t ~ o f ~ P r o s t h e t i c ~ D e n t a l ~ S c i e n c e s, ~ C o l l e g e ~ o f ~ D e n t i s t r y, ~ J a z a n ~ U n i v e r s i t y, ~(K S A) ~}$ \\ ${ }^{2}$ Senior Dental Technician, Subharti Dental college, Subharti University, India \\ * Corresponding Author \\ Khurshid A Mattoo \\ Email:drkamattoo@rediffmail.com
}

\begin{abstract}
Very often in academic practice, students ignore, work approval by their respective supervisor. During complete denture fabrication, denture trial is a clinical procedure that most of graduate students consider petite clinical procedure, thereby neglecting many things that are to be clinically verified. An elderly female reported to the department that she was not satisfied with the esthetics of the complete denture delivered to her. The female patient was advised new complete denture fabrication which she rightly rejected. After evaluation of the vertical and centric relation with current centric occlusion, it was decided that the same denture can be corrected. This article describes a simple clinical technique to replace anterior teeth of the existing denture.

Keywords: artificial teeth, polymerization, articulator, complete denture, centric relation.
\end{abstract}

\section{Introduction}

The denture trial is a three eyed clinical procedure that needs to be verified by the dentist firstly, followed by approval by the patient and then his close associate. The importance of perfection and verification of jaw relation records has been emphasized in all textbooks. ${ }^{1-3}$ Therefore, even denture trial is a procedure where jaw relations have to be perfected. Only when one is sure after verification, he should proceed to the next step. Denture trial is the last stage where modifications can be accommodated. Nevertheless, in academic practice, there are times when teachers are busy with students and there are times when students bypass the supervision. This article describes a case report of an elderly female patient who received a complete denture prosthesis with flared anterior teeth. Emergency correction in such case is described. An outline of denture trial has also been tabled.

\section{Case report}

A female patient aged 64 years, reported to the undergraduate OPD of the department of Prosthodontics with chief complaint of new denture falling whenever she would speak. The complete denture was delivered to her by an undergraduate student who had neglected the academic protocol and delivered the denture after galloping through try in procedure. The patient was advised for remaking of a new denture which patient rejected as it was difficult for her to go through the entire procedure again. The patient was referred to the post graduate clinic of the department, where after preliminary verification of vertical dimensions and centric relation of the denture it was decided that an attempt 
will be made to replace the faulty proclined anterior teeth with a new one but the patient would receive the denture after one day which she happily agreed. Medical, dental, social, drug and other histories were non-contributory. This was the patient's first denture and had lost remaining few teeth due to mobility six months back.

At the outset, the patient was asked to wear the existing complete denture (Fig 1a) and perform oral functions (Fig 1b). Maxillary anterior teeth were visible to the cervical margin and while smiling the denture would fall. All objectives of impression making were verified following which centric relation and vertical dimensions were verified (Fig 1c). Reasons for denture failure were proclined anterior teeth with excessive visibility (Fig1d). Excess proclination activates orbicularis oris which in turn pushes the denture backwards and downwards.

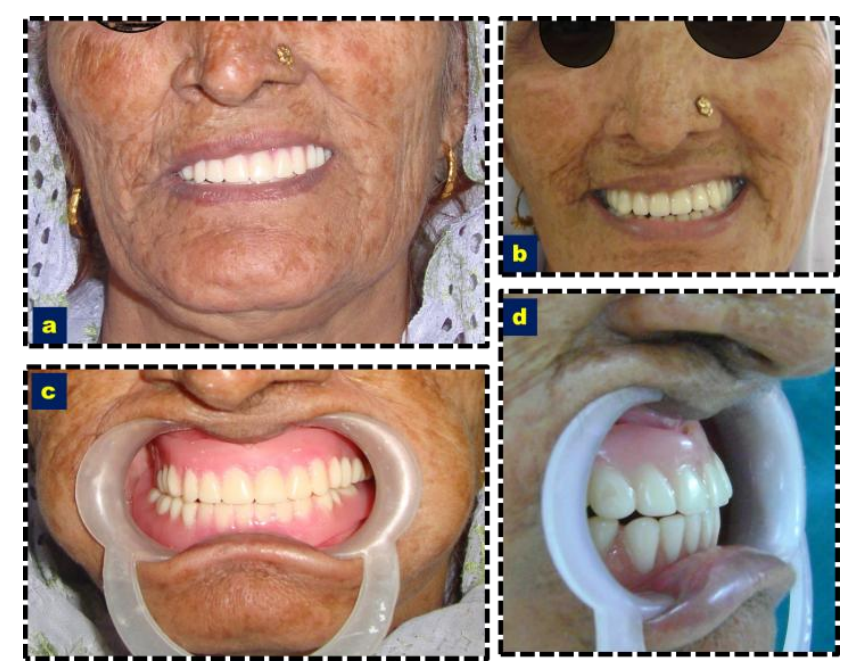

Figure 1: Maxillary and mandibular denture showing extreme visiblity, correct centric and vertical and proclined anteriors

\section{Procedure}

The dentures were checked for peripheral extensions, retention, stability, posterior palatal seal, vertical dimensions and centric occlusion (relation with centric relation). A new centric relation record was made using bite registration paste (O-Bite, DMG-Germany) (Fig 2a). Denture with the new interocclusal centric record was then mounted on an articulator (mean value) similar like a clinical remount procedure. All the maxillary and mandibu- lar anterior teeth were removed using an acrylic trimmer. This was replaced by modelling wax (Rolex, India). The profile contour of modelling wax was then re-established clinically on the patient. New teeth were then arranged in conventional manner (Fig 2 b,c). A denture trial was done (Outlined in Table 1) and after her approval the dentures were invested in a conventional way except one modification. The entire denture was covered in plaster except the teeth that were attached to the denture with wax (Fig 2 d). Heat cure denture base acrylic (DPI-Heat cure, Dental products of India Ltd, Mumbai, India) was then added in the area and after trial closure and bench curing, the denture was processed using a long cycle (100 degrees centigrade for 8 hours) for denture processing. The denture was retrieved next day and finished and polished (Fig 2e). The patient was informed about the drawbacks of double curing, although long curing cycle was used to minimize such drawbacks. The patient was satisfied with the immediate correction that was offered to her.

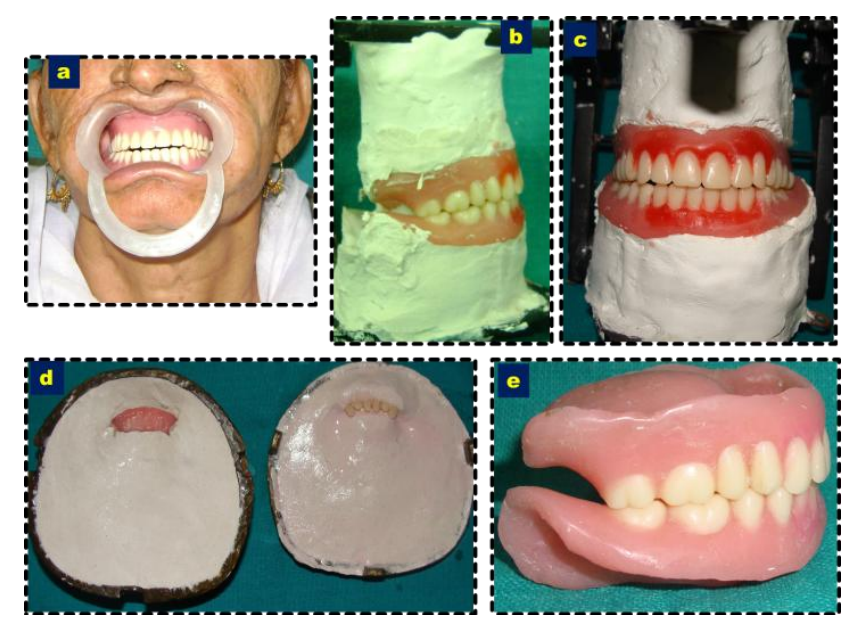

Figure 2: Clinical and laboratory procedure involved in correction. (Refer text for details)

\section{Discussion}

Over the years in various academic set ups, the author has observed a decline in the quality of denture trial procedures which is why it has prompted the author to use this case as a good opportunity to review this important clinical procedure for this discussion. A brief outline is given in table 1. Denture trial is a clinical procedure wherein the dentist needs to verify all 
aspects of the denture tooth set up i:e the appearance, phonetics, occlusal relationships and patient comfort. Most authors recommend two trial appointments (anterior/posterior or initial/final) and one should practice the same. ${ }^{1,3}$

Among various complete denture failures, the failure in this case was iatrogenic and could have been easily avoided with little patience and care. Most of the dental students, are supposed to arrange the teeth themselves under supervision at all times. Doing laboratory work either at residence or by dental technicians snatches the learning opportunity. Such academic practice is not advisable during learning, because while doing laboratory work, there is need of correction all the time. While arranging anterior teeth, if a single tooth is arranged outside the confines of the occlusal rims, then as arrangement progresses the error gets magnified. In this case, this was the main reason of arranging proclined and flared teeth.

Table 1: An outline of complete denture try in procedure

\begin{tabular}{|l|l|}
\hline 1) & $\begin{array}{l}\text { Preparation for denture trial } \\
\text { Verify teeth arrangement first on the articulator } \\
\text { Place an arrangement of teeth near the patient and observe } \\
\text { his reaction } \\
\text { Stimulate salivary secretion by placing mandibular denture, } \\
\text { first, then place maxillary }\end{array}$ \\
\hline 2) & $\begin{array}{l}\text { General verification } \\
\text { Altered flange thickness due to wax up affects fullness } \\
\text { Rocking of trial denture }\end{array}$ \\
\hline 3) & $\begin{array}{l}\text { The lower denture by itself } \\
\text { Peripheral outline - buccal, labial, lingual, posterior } \\
\text { extension, over and under extension }\end{array}$ \\
Stability to occlusal stresses \\
Tongue space \\
Occlusal plane height
\end{tabular}

Complete denture prosthesis is made up of heat cure denture acrylic resin and has been traditionally repaired with different materials like self-cure and heat cure denture base resins, light polymerized resin (VLP) and microwave resins (MW). ${ }^{4-7}$ Although auto cure acrylic resin is a commonly used repair material but in this case the repair was done using heat cure acrylic for better durability, avoid mismatching and high strength. ${ }^{8}$ However, to minimize distortion due to reheating, a long curing cycle of polymerization was used. In this case, because the vertical dimensions and the centric were correct the decision to replace anterior teeth was taken. In case, the vertical and centric would have not been correct then there are two options, either remake the denture or use the present denture as a special tray or a trial denture base.

\section{Conclusion}

Every clinical and laboratory procedure in fabrication of the complete denture prosthesis has its own significance and any error in one step leads to failure of the entire prosthesis. Fortunately, in Prosthodontics there are methods compensating one's errors, but in such cases the property of the final prosthesis gets compromised.

\section{Acknowledgements}

The efforts of the patient during fabrication of her prosthesis that ultimately failed and her resolve to get it corrected is highly acknowledged.

\section{References}

1. George A. Zarb. Prosthodontic treatment for edentulous patients: complete dentures and implant supported prosthesis, 12th Ed. Mosby. 366-68

2. Sheldon Winkler. Essential of Complete Denture Prosthodontics. pp 38,63,90

3. Heartwell C, Rahn AO. Syllabus of Complete Dentures. 4th ed.; Lea \& Febiger: 309,327,344

4. Faot F, Da Silva WJ, Da Rosa RS, Del Bel Cury AA, Garcia RC (2009) Strength of denture base resins repaired with auto-and 
visible light-polymerized materials. J

Prosthodont 18(6): 496-502

5. Ng ET, Tan LH, Chew BS, Thean HP

(2004) Shear bond strength of microwaveable acrylic resin for denture repair. J Oral Rehabil 31 (8): 798-802.

6. Gad MM, Rahoma A, Al-Thobity AM, ArRejaie AS (2016) Influence of incorporation of $\mathrm{ZrO}$ nanoparticles on the repair strength of polymethyl methacrylate denture bases. Int J Nanomedicine 11: 56335643

7. Rached RN, Powers JM, Del Bel Cury AA (2004) Efficacy of conventional and experimental techniques for denture repair. J Oral Rehabil 31(11): 1130-1138.

8. Dental laboratory procedures - Complete dentures:Rudd and Morrow, Mosby . pp 345,378 